\title{
The Computing of Intersectant Relations for Its Strength Problem on Damage and Fracture to Materials with Short and Long Crack
}

\author{
Yangui Yu, ${ }^{1}$ Yiming Sun, ${ }^{2}$ Yanghui $M{ }^{2},{ }^{2}$ and Feng $\mathrm{Xu}^{3}$ \\ ${ }^{1}$ Zhejiang GuangXin New Technology Application Academy of Electromechanical and Chemical Engineering, 13E East Edifice, \\ 160 International Garden Tiannushan Road, Hangzhou 310007, China \\ ${ }^{2}$ Zhejiang Science and Technology University, 1 Xiaoheshan Road, Hangzhou 310023, China \\ ${ }^{3}$ Zhejiang Vocational College of Commerce, 470 Bingwen Road, Hangzhou 310053, China \\ Correspondence should be addressed to Yangui Yu, gx_yyg@126.com
}

Received 30 January 2011; Accepted 27 March 2011

Academic Editor: J.-L. Marcelin

Copyright ( $) 2011$ Yangui Yu et al. This is an open access article distributed under the Creative Commons Attribution License, which permits unrestricted use, distribution, and reproduction in any medium, provided the original work is properly cited.

\begin{abstract}
Adopt two types of damage variables, $a$ and $D$, and make the bidirectional combined coordinate system and the bidirectional curves in the whole process, describing their damage evolutive behaviors on fatigue damage-fracture to elastic-plastic steels; communicate the cross-referencing between their computing models and between describing curves at each stage among varied disciplines; bring forward a viewpoint about the driving force of material damage, that is the damage stress factor at crack forming stage, Provide the computation expressions and computing methods of the strength problem of materials with short crack and long crack at each stage; reveal the geometrical and the physical meaning of force triangle and its edge vector at each stage, Provide the conversion methods between the variables, the equations, the material constants and the dimensional units; Indicate the physical and the geometrical meanings for some key parameters. This will be having practical significance for promoting developing, and applying each discipline.
\end{abstract}

\section{Introduction}

As is now well known, we adopt the crack size $a$ as a variable in the fracture mechanics to describe crack growth process undergoing damage for a material and we adopt a damage variable $D$ in the damage mechanics to describe an evolutive process undergoing damage for one. Either the sign $a$ or the sign $D$ are all virtually damage variables so, we could also adopt the damage $D$ to describe the evolutive law of a structure material with crack. References [1-3] had made out such research. In each discipline we have all in-house features and its advantages. If we can communicate and convert corresponding relations for that among the damage variables, and the equations, the material constants, the dimensional units which describe the material behavior for varied discipline and provide some conversion methods, thus we are also able to adopt the same variables $D_{1}$ and $D_{2}$ or the variable $a_{1}$ and $a_{2}$ to compute the strength and the life at each stage or even in overall process for structures and materials undergoing fatigue damage $[4,5]$. And the conventional materials and damage mechanics are made by inheritance and development and the modern one is made by all better combination and application. Based on this aim THE authors adopt the mathematical derivation and computational analyses used with computer by long-range research, educe a series of the computation expressions and the computing methods. Thus, this may be having practical significance for promoting, developing, and applying of some disciplines.

\section{Bidirectional Combined Coordinate System and Bidirectional Curves in the Whole Process}

In some of branch disciplines on fatigue-damage fracture, for finding their correlations among variables, curves, equations, and material constants of describing material behaviors at each stage and for connecting their relations to each other, we must put up analysis and developments for a number of 
problems that are above mentioned. Here, it is by means of bidirectional combined coordinate system that is, adopted in Figure 1 [6] we express the damage evolving process of material behavior at each stage and in the whole course, which consists of six abscissa axes $O_{\mathrm{I}^{\prime \prime}}^{\prime}, O_{\mathrm{I}^{\prime}}, O_{1 \mathrm{I}}, O_{2 \mathrm{II}}, O_{3 \mathrm{III}}$, and $\mathrm{O}_{4} \mathrm{IV}$ and two bidirectional ordinate axis $\mathrm{O}_{1} \mathrm{O}_{4}$ and $O_{1}^{\prime} \mathrm{O}_{4}^{\prime}$. Between the axes $O_{\mathrm{I}^{\prime \prime}}^{\prime}$ and $O_{1 \mathrm{I}}$, it is the calculation domain of the conventional material mechanics; between the axes $O_{I^{\prime \prime}}^{\prime}$ and $O_{\mathrm{I}^{\prime}}$, it is the calculation domain of the current ultrahigh cycle fatigue; among the axes $O_{\mathrm{I}^{\prime}}, O_{1 \mathrm{I}}$, and $\mathrm{O}_{2 \mathrm{II}}$, it is the calculation domain of the damage mechanics and the microfracture mechanics; between the axes $\mathrm{O}_{3 \mathrm{III}}$ and $\mathrm{O}_{4 \mathrm{IV}}$, it is calculation domain of the macrofracture mechanics; Between the axes $\mathrm{O}_{2 \mathrm{II}}$ and $\mathrm{O}_{3 \mathrm{III}}$, it is all applicable calculation domain for the microfracture mechanics and macrofracture mechanics. The upward direction along the ordinate axis is presented as damage evolving rate $d D / d N$ or crack growth rate $d a / d N$ (that can also carve up the damage evolving rate $d D_{1} / d N_{1}$ or short crack growth rate $d a_{1} / d N_{1}$ at crack forming stage or the damage evolving rate $d D_{2} / d N_{2}$ or long crack growth rate $d a_{2} / d N_{2}$ at crack growth stage), and the downward direction is presented as each stage life $2 \mathrm{~N}$. The distance $O^{\prime} O$ between axis $O_{\mathrm{I}^{\prime \prime}}^{\prime}$ and $O_{\mathrm{I}^{\prime}}$ is shown as the region of the nominal stress $S$ or remote stress $\sigma_{o}$; the distance $\mathrm{O}^{\prime} \mathrm{O}_{2}$ between axis $\mathrm{O}_{\mathrm{I}^{\prime \prime}}^{\prime}$ and $\mathrm{O}_{2 \mathrm{II}}$ is shown as the region from uncrack to microcrack initiation; the distance $\mathrm{O}_{2} \mathrm{O}_{3}$ between axes $\mathrm{O}_{2 \mathrm{II}}$ and $\mathrm{O}_{3 \mathrm{III}}$ is shown as the region relative to life $N_{\mathrm{oi}}{ }^{\text {mic-mac }}$ from microcrack growth to macrocrack forming. Consequently, the distance $\mathrm{O}^{\prime} \mathrm{O}_{3}$ is shown as the region relating to life $N_{\text {mac }}$ from grains size to microcrack initiation until macrocrack forming; the distance $\mathrm{O}^{\prime} \mathrm{O}_{4}$ is shown as the region relating to the lifelong life $2 \mathrm{~N}$ from micro-crack initiation until fracture of structure material. The coordinate system combined from upward axis $\mathrm{O}^{\prime} \mathrm{O}_{4}$ and abscissa axes $O_{\mathrm{I}^{\prime}}, O_{1 \mathrm{I}}$, and $O_{2 \mathrm{II}}$ is presented to be the relationship between the damage evolving rate $d D_{1} / d N_{1}$ (or the short crack growth rate $d a_{1} / d N_{1}$ ) and the damage stress factor amplitude $\Delta H / 2$ (or damage strain factor amplitude $\Delta I / 2$ ) at crack forming stage; the coordinate system combined from $\mathrm{O}^{\prime} \mathrm{O}_{4}$ and $\mathrm{O}_{3 \mathrm{III}}\left(\mathrm{O}_{4 \mathrm{IV}}\right)$ at the same direction is presented to be the relationship between macrocrack growth rate and stress intensity factor amplitude $\Delta K / 2, J$-integral amplitude $\Delta J / 2$, and crack tip displacement amplitude $\Delta \delta_{t} / 2\left(d a_{2} / d N_{2}-\right.$ $\Delta K / 2, \Delta J / 2$ and $\left.\Delta \delta_{t} / 2\right)$ at macro-crack growth stage. The coordinate system combined from downward ordinate axis $\mathrm{O}_{4} \mathrm{O}_{1}$ and abscissa axes $\mathrm{O}_{2 \mathrm{II}}$, and $\mathrm{O}_{3 \mathrm{III}}$ is presented as the relationship between the $\Delta H / 2-, \Delta K / 2$-amplitude, and the life $2 \mathrm{~N}$ (or between the $\Delta \varepsilon_{p} / 2-, \Delta \delta_{t} / 2$-amplitude, and the life $2 \mathrm{~N})$. The curve abcd is the ultra-high cycle fatigue one to correspond to stress below fatigue limit. On abscissa $\mathrm{O}_{3 \mathrm{III}}$, point $A_{1}$ is corresponding to fatigue strength coefficient $\sigma_{f}^{\prime}$; point $C_{1}$ is corresponding to fatigue ductility coefficient $\varepsilon_{f}^{\prime}$; point $F$ is corresponding to ultra-high cycle fatigue strength coefficient $\sigma_{\text {uhf }}^{\prime}$. The $A B A_{1}$ shows the varying regularities of elastic material behaviors as under high cycle loading at macro-crack forming stage; positive direction $A B A_{1}$ shows the relation between $d D_{1} / d N_{1}$ (or $d a_{1} / d N_{1}$ ) and $\Delta H / 2$; inverted $A_{1} B A$ shows the relation between the $\Delta H / 2$ and
$2 \mathrm{~N}$. The curve $C B C_{1}$ shows the varying regularities of plastic material behaviors, as is under low-cycle loading at macrocrack forming stage; positive direction $C B C_{1}$ shows the relation between $d a_{1} / d N_{1}$ and $\Delta I / 2$; inverted $C_{1} B C$ shows the relation between the $\Delta \varepsilon_{p} / 2-2 \mathrm{~N}$. And the curve $A_{1} A_{2}$ at crack growth stage is showed as under high cycle loading: positive direction $A_{1} A_{2}$; shows $d a_{2} / d N_{2}-\Delta K / 2(\Delta J / 2)$; inverted $A_{2} A_{1}$, shows the relation between the $\Delta K / 2$ and $\Delta J / 2-2 \mathrm{~N}$. The $C_{1} C_{2}$ shows the positive direction relation between the $d a_{2} / d N_{2}$ and $\Delta \delta_{t} / 2$ under low-cycle loading, inverted $C_{2} C_{1}$, shows the relation between $\Delta \delta_{t} / 2(\Delta J / 2)$ and $2 \mathrm{~N}$. And it should point that the $A A_{1} A_{2}$ (curve $11^{\prime}$ ) is expressed for the curve under symmetrical cycle loading (i.e., under zero mean stress); the $D D_{1} D_{2}$ (curve $33^{\prime}$ ) is expressed for the curve under unsymmetrical cycle loading (i.e., under nonzero mean stress).

\section{Relations among Force Triangles and Relations among Edge Vectors of Force Triangle Itself at Each Stage}

Due to extent of material undergone damage at each stage is different and due to the variance in the material behaviors after undergoing damage, the rigidity of material is also different to ensue from change, so the force triangles consist of edge vectors at different stages which are also varied relationships among force triangles, and relationships among the edge vectors themselves at each stage, their geometrical and physical meanings are all compiled in Table 1 . We can make out from the force triangle in each area from Figure 1 find the mathematic model of driving force is different in each discipline. The driving force seen from force triangle between the axes $O^{\prime} I^{\prime \prime}$ and $O I^{\prime}$ is the damage stress intensity factor under ultra-high cycle fatigue. We should also point out that this is the calculation domain in micro-damage mechanics or in conventional material mechanics

$$
\begin{gathered}
\Delta G_{\mathrm{uh}}=\Delta \sigma_{\mathrm{uh}} \cdot a_{\mu}^{1 / n}, \\
\Delta G_{\mathrm{uh}}^{\prime}=\Delta \sigma_{\mathrm{uh}} \cdot D_{\mu}^{1 / n},
\end{gathered}
$$

where the $\Delta G_{\mathrm{uh}}$ and $\Delta G_{\mathrm{uh}}^{\prime}$ are, respectively, the microcrock stress intensity factor or the microdamage stress intensity factor under ultra-high cycle fatigue to correspond a crystal grain or microdamage defect $a_{\mu}\left(D_{\mu}\right)$ which is originated from interior materials. And the mathematic models of driving force between the axes $O_{1 \mathrm{II}}$ and $\mathrm{O}_{3 \mathrm{III}}$ are the stress intensity factor range $\Delta H_{1}$ of shortcrack or the damage stress intensity factor range $\Delta H_{1}^{\prime}$.

$$
\Delta H_{1}=\Delta \sigma_{1} \cdot \sqrt[m_{1}]{a_{1}}
$$

or

$$
\Delta H_{1}^{\prime}=\Delta \sigma_{1} \cdot \sqrt[m_{1}]{D_{1}}
$$

that is calculation domain of the microfracture mechanics or damage mechanics. And the mathematic models of driving force between the axes $\mathrm{O}_{3 \mathrm{III}}$ and $\mathrm{O}_{4 \mathrm{IV}}$ are the stress intensity 


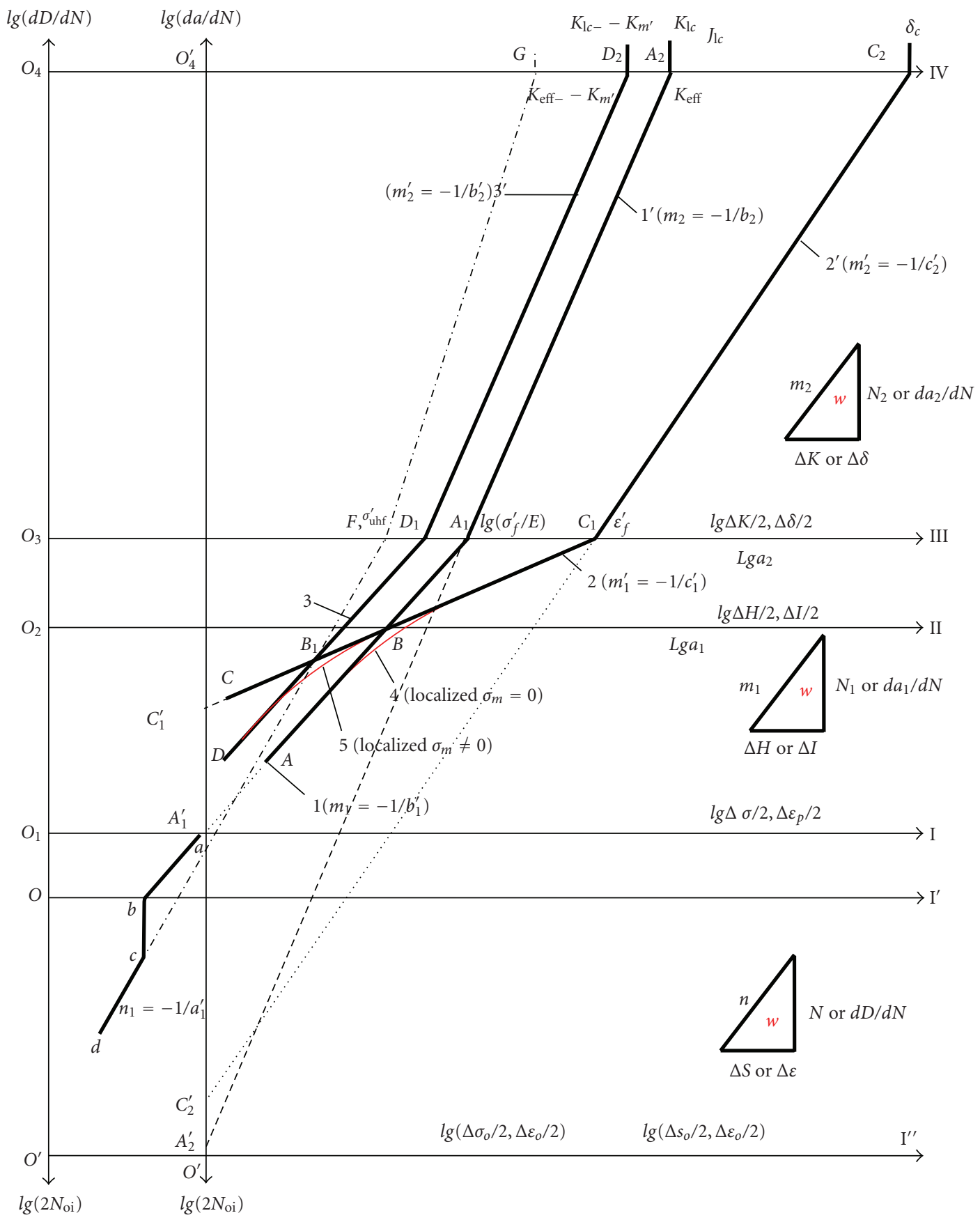

Figure 1: Bidirectional combined coordinate system and bidirectional curves in the whole process.

factor range $\Delta K_{2}$ of longcrack or the damage stress intensity factor range $\Delta K_{2}^{\prime}$ at the second stage

$$
\Delta K_{2}=\Delta \sigma \cdot \sqrt{\pi a_{2}},
$$

or

$$
\Delta K_{2}^{\prime}=\Delta \sigma \cdot \sqrt{\pi D_{2}}
$$

that is calculation domain of the macro-fracture mechanics. Relations among force triangles can be expressly made out in Figure 1; the relations among edge vectors of force triangle iteself and their geometrical and physical meaning at each stage are all compiled in Table 1.

\section{Computing the Damage Strength for Elastic-Plastic Material under High-Cycle Fatigue}

Based upon above-mentioned viewpoints we bring forward the computation expressions and calculation methods of strength for elastic-plastic steels which are the material 
TABLE 1: Relations among the edge vectors of the force triangle iteself and their geometrical and physical meanings at each stage.

\begin{tabular}{|c|c|c|c|c|}
\hline \multirow[b]{2}{*}{$\begin{array}{l}\text { Ubiety area of } \\
\text { triangle }\end{array}$} & \multicolumn{2}{|c|}{ Forward direction } & \multicolumn{2}{|c|}{ Reverse direction } \\
\hline & $\begin{array}{l}\text { Geometrical meaning of } \\
\text { edge vector }\end{array}$ & $\begin{array}{l}\text { Physical meaning of edge } \\
\text { vector }\end{array}$ & $\begin{array}{l}\text { Geometrical meaning of } \\
\text { edge vector }\end{array}$ & $\begin{array}{l}\text { Physical meaning of edge } \\
\text { vector }\end{array}$ \\
\hline \multirow{4}{*}{$\begin{array}{l}\text { Triangle between } \\
\text { the axes } O^{\prime} I^{\prime \prime} \text { and } \\
O I^{\prime}\end{array}$} & Level edge & Driving force & Level edge & Driving force \\
\hline & Vertical edge & Damage rate & Vertical edge & Life of one cycle \\
\hline & Bevel edge (slope) & Elastoplastic & Bevel vector (slope) & Elastoplastic \\
\hline & Area of triangle & Power $(w)$ & Area & Work $(w)$ in one cycle \\
\hline \multirow{4}{*}{$\begin{array}{l}\text { Triangle between } \\
\text { the axes } O_{1 \mathrm{I}} \text { and } \\
\mathrm{O}_{3 \text { III }}\end{array}$} & Level edge & Driving force & Level edge & Driving force \\
\hline & Vertical edge & Damage rate & Vertical edge & Life of one cycle \\
\hline & Bevel edge (slope) & Elastoplastic & Bevel vector (slope) & Elastoplastic \\
\hline & Area of triangle & Power $(\mathrm{w})$ & Area of triangle & Work (w) in one cycle \\
\hline \multirow{4}{*}{$\begin{array}{l}\text { Triangle between } \\
\text { the axes } O_{3 I I I} \text { and } \\
O_{4 \mathrm{IV}}\end{array}$} & Level edge & Driving force & Level edge & Driving force \\
\hline & Vertical edge & Damage rate & Vertical edge & Life of one cycle \\
\hline & Bevel edge (slope) & Elastoplastic and stiffness & Bevel vector (slope) & Elastoplastic and stiffness \\
\hline & Area of triangle & Power & Area of triangle & Work in one cycle \\
\hline
\end{tabular}

behaviors undergoing fatigue damage at different stages. And we proportionally analyze for the cross-referencing between their equations, material constants, and dimensional units and also explain conversion methods between them.

\subsection{Computing of Strength for Material with Crack}

4.1.1. Computing of Strength at the First Stage. About computing the material strength with short crack, many researchers had presented varied computing models and made out valuable contributions [7, 8]. Murakami [9] provides the computation expression as follows:

$$
K_{\operatorname{Imax}} \cong 0.65 \sigma_{0} \sqrt{\pi \sqrt{\text { area }}}
$$

And research and analysis of the driving force of force triangle in Figure 1 and according to above explanation and the present author provide again a computational model to describe stress-strain about the tip of short crack that is the stress intensity factor at the first stage as following [10-12]:

$$
H_{1}=y_{1} \sigma \cdot \sqrt[m_{1}]{a_{1}} \leq H_{\mathrm{mac}}\left(\sqrt[m_{1}]{m} \cdot \mathrm{MPa}\right),
$$

where

$$
H_{\mathrm{mac}}=\sigma \cdot \sqrt[m_{1}]{a_{\mathrm{mac}}}\left(\sqrt[m_{1}]{m} \cdot \mathrm{MPa}\right)
$$

$H_{\text {mac }}=$ Critical stress intensity factor of short crack that is corresponding to macro-crack size at about the threshold level $\Delta K_{\text {th }}$ and more than one, that is artificially definite according to the size of structure member.

$y_{1}$ is a correction coefficient concerned with shape and size, for example, of a structure member. And it became the damage stress intensity factor at the same stage when we adopt damage variable $D_{1}$ to describe [13]

$$
H^{\prime}=y_{1} \sigma \cdot \sqrt[m_{1}]{D_{1}} \leq H_{\mathrm{mac}}^{\prime}, \quad\left(\mathrm{MPa} \sqrt[m_{1}]{D_{1}}\right) \text { or } \mathrm{MPa}
$$

where

$$
H_{\text {mac }}^{\prime}=\sigma \cdot \sqrt[m_{1}]{D_{\text {mac }}} \quad\left(\mathrm{MPa} \sqrt[m_{1}]{D_{1}}\right) \text { or } \mathrm{MPa}
$$

$H_{\mathrm{mac}}^{\prime}$ : Critical damage stress intensity factor that is equivalent to the $H_{\text {mac }}$. $D_{\text {mac }}$ : Critical damage level that is equivalent to $a_{\mathrm{mac}}$; if $a_{\mathrm{mac}}=0.7 \mathrm{~mm}$, then $D_{\mathrm{mac}}=0.7$.

Conversion method between variables $a$ and $D$ and between the dimensional units defines $1 \mathrm{~mm}$ equivalent to one damage unit (nondimensional value), $1 \mathrm{~m}$ equivalent to 1000 damage unit. If critical $a_{\mathrm{mac}}=0.7 \mathrm{~mm}$, then critical damage value of the equivalent is $D_{\mathrm{mac}}=0.7$ damage unit. And define that $a_{0}<a_{1} \leq a_{\mathrm{mac}} ; D_{0}<D_{1} \leq D_{\mathrm{mac}}$. The $D_{0}$ is an initial damage value corresponding to micro-crack size $a_{0}$, and it is advised to take the average value of 10 crystal sizes or to take the maximum size of crystal size. It should also be pointed out that the stresses are all local ones in (2)-(5) and (7)-(10).

4.1.2. Computing of Strength at the Second Stage. The computational model to describe stress strain about the tip of long crack at the second stage had been provided by famous scientists Broek and Hellan as follows $[14,15]$ :

$$
K_{\mathrm{I}}=\left(K_{2}\right)=y_{2} \cdot \sigma \sqrt{\pi a_{2}}<K_{\mathrm{I} c}\left(=K_{2 c}\right)(\sqrt{m} \cdot \mathrm{MPa}) \text {, }
$$

$$
K_{\mathrm{I} c}=K_{2 c}=\sigma \sqrt{\pi \cdot a_{2 c}}, \quad(\sqrt{m} \cdot \mathrm{MPa}),
$$

where $K_{I c}\left(=K_{2 c}\right)=$ Critical stress intensity factor of long crack $y_{2}$ is a correctional coefficient concerned with the shape of crack and shape and size of structure member. And it becomes the damage stress intensity factor at the same stage if we adopt damage variable $D_{2}$ to describe $[16,17]$

$$
\begin{gathered}
K_{2}^{\prime}=y_{2} \cdot \sigma \sqrt{\pi D_{2}}<K_{2 c}^{\prime}, \quad\left(\mathrm{MPa} \sqrt[m_{1}]{D_{1}}\right) \text { or } \mathrm{MPa} \\
K_{2 c}^{\prime}=\sigma \sqrt{\pi D_{2 c}}, \quad\left(\mathrm{MPa} \sqrt{D_{2}}\right) \text { or } \mathrm{MPa}
\end{gathered}
$$

$K_{2 c}^{\prime}$ is a critical damage stress intensity factor equivalent to the $K_{\mathrm{I} c}\left(K_{2 c}\right) . D_{2 c}$ is a critical damage value correspondent to the critical crack size $a_{2 c}$. 
Conversion method between variables $a_{2}$ and $D_{2}$ and between the dimensional units at the second stage is the same as the first stage. It should be pointed out that the dimensional unit of the damage stress intensity factor $H^{\prime}$ and the $K_{2}^{\prime}$ at each stage become identical with the unit of stress because the dimensional unit between the variables $a$ and $D$ is converted.

It should be pointed out that both the values between the stress intensity factor of short-crack and the stress intensity of long crack are different under the condition of the same crack size (e.g., $a_{1}=a_{2}=0.1 \mathrm{~mm}$ ) because the mechanisms of material damage and because their mathematical models and dimensional units of both driving forces are all different. But both growth rates at the turning point from short crack to long crack should be accordant or near.

\section{Computing Example}

A pressure vessel adopts the steel $16 \mathrm{MnR}$ to make its strength limit of material $\sigma_{b}=545 \mathrm{MPa}$, yield limit $\sigma_{y}=349 \mathrm{MPa}$, the strain-hardening exponent $n=0.136$, fatigue strength exponent in short crack growth $m_{1}=11.478$, threshold level $\Delta K_{\text {th }}=6.87 \mathrm{MPa} \sqrt{m}$, critical stress intensity factor $K_{1 c}=97.3 \mathrm{MPa} \sqrt{m}=K_{2 c}=K_{\mathrm{Ic}}=97.3(\mathrm{MPa} \sqrt{m})$, critical damage stress intensity factor $K_{2 c}^{\prime}=97.3 \mathrm{MPa} \sqrt{D_{2}}$ equivalent to the $K_{\mathrm{Ic}}\left(K_{2 c}\right)$, the critical stress intensity factor $H_{\text {mac }}=350 \sqrt[m_{1}]{m}$ and the damage stress intensity factor $H_{\text {mac }}^{\prime}=350\left(\mathrm{MPa} \sqrt[m_{1}]{D_{1}}\right)$ of short crack corresponding to the threshold level $\Delta K_{\mathrm{th}}$, and the mean sizes $a_{0}=20 \sim 30 \mu \mathrm{m}$ of crystal grains; its working stress is $280 \mathrm{MPa}$ of pressure vessel and local stress is $840 \mathrm{MPa}$ at focal point of stress. Try respectively, to compute the stress intensity factor $H$ and the damage stress intensity factor $H^{\prime}$ at short crack size $a_{0}=100 \mu \mathrm{m}$ undergone after damage for a crystal grain and the stress intensity factor $K_{2}=K_{\mathrm{I}}$ and the damage stress intensity factor $K_{2}^{\prime}$ at long crack size $a_{2}=2 \mathrm{~mm}$. Computing approach is as follows.

\subsection{Computing the Stress Intensity Factor $H$ and the Damage Stress Intensity Factor $H^{\prime}$ for Short Crack}

5.1.1. Computing the Stress Intensity Factor $H$ for Short Crack. According to (7), select the computing parameter: $a_{1}=$ $100 \mu \mathrm{m}=1.0^{-4} \mathrm{~m}$; the local stress is $840 \mathrm{MPa}$ at focal point of stress undergone damage; If we take $y_{1}=1.1$,

$$
\begin{aligned}
H_{1} & =y_{1} \sigma \cdot \sqrt[m_{1}]{a_{1}}=1.1 \times 840 \times \sqrt[11.478]{100 \mu \mathrm{m}} \\
& =1.1 \times 840 \times \sqrt[11.478]{1.0^{-4} \mathrm{~m}} \\
& =414.41\left(\sqrt[m_{1}]{m}\right) .
\end{aligned}
$$

This results in

$$
H_{1}=414.41\left(\sqrt[m_{1}]{m}\right)>H_{\mathrm{mac}}^{\prime}=350\left(\sqrt[m_{1}]{m} \mathrm{MPa}\right)
$$

So this short crack is growth.
5.1.2. Computing of the Damage Stress Intensity Factor $H^{\prime}$ for Short Crack. According to (9), when the $a_{1}=100 \mu \mathrm{m}=$ $1.0^{-4} \mathrm{~m}$, equivalent damage value of short crack is the $D_{1}=$ $100=1.0^{-4}$ (damage unit).

So

$$
\begin{aligned}
H_{1} & =y_{1} \times \sigma \cdot \sqrt[m_{1}]{D_{1}} \\
& =1.1 \times 840 \times \sqrt[11.478]{100} \\
& =1.1 \times 840 \times \sqrt[11.478]{1.0^{-4}} \\
& =414.41\left(\mathrm{MPa} \sqrt[m_{1}]{D}\right) \text { or }(\mathrm{MPa})
\end{aligned}
$$

This results in

$$
H_{1}=414.41\left(\mathrm{MPa} \sqrt[m_{1}]{\mathrm{D}}>H_{\mathrm{mac}}^{\prime}\right)=350(\mathrm{MPa}) .
$$

So this short crack is also growth.

\subsection{Computing the Stress Intensity Factor $K_{2}=K_{I}$ and the}

Damage Stress Intensity Factor $K_{2}^{\prime}$ for Long Crack

5.2.1. Computing the Stress Intensity Factor $K_{2}$ for Long Crack. According to (11), select a parameter, take the correction coefficient $y_{2}=1.05, a_{2}=2 \mathrm{~mm}$, working stress $\sigma=280 \mathrm{MPa}$

$$
\begin{aligned}
K_{2} & =K_{\mathrm{I}}=y_{2} \times \sigma \times \sqrt{\pi \cdot a_{2}} \\
& =1.05 \times 280 \times \sqrt{\pi \times 0.002} \\
& =23.30(\mathrm{MPa} \sqrt{m}) .
\end{aligned}
$$

This results in

$$
K_{2}=23.30<K_{2 c}^{\prime}=K_{\mathrm{I} c}=97.3(\mathrm{MPa} \sqrt{m}) .
$$

So the pressure vessel is safe.

5.2.2. Computing the Damage Stress Intensity Factor $K_{2}^{\prime}$ for Long Crack. According to equation (13), take the computing parameter $y_{2}=1.05$; when take $a_{2}=2 \mathrm{~mm}$, the equivalent damage value of long crack is $D_{2}=2000=2 \cdot 0^{-3}$ (damage unit).

So

$$
\begin{aligned}
K_{2} & =K_{\mathrm{I}}=y_{2} \times \sigma \sqrt{\pi \cdot D_{2}} \\
& =1.05 \times 280 \times \sqrt{\pi \times 0.002} \\
& =23.30(\mathrm{MPa} \sqrt{D}) \text { or }(\mathrm{MPa}) .
\end{aligned}
$$

This results in

$$
K_{2}=23.30<K_{2 c}^{\prime}=97.3(\mathrm{MPa}) .
$$

So the pressure vessel is also safe. 


\section{Summarization}

The bidirectional combined coordinate system, the bidirectional curves in the whole process and their force triangles at each stage are important scientific method and tool to communicate the cross-referencing which is to describe the evolutive process of a material behavior undergoing of the fatigue damage in each of the disciplines, which are able to make available communications and conversions for those complicated correlations among some variables, some equations, curves, and dimensional units, which are clearely able to explain the geometrical and physical meanings for the key parameters. Thus, it is also able to adopt same variables $D_{1}$ and $D_{2}$ or the variables $a_{1}$ and $a_{2}$ to compute the strength and the lift at each stage or even in overall process for structures and materials undergoing a fatigue damage. And the conventional material and damage mechanics are able of making inheritance and development, and the modern one are all able to make better combination and application. Thus, that may be having practical significance for promoting developing, and applying some disciplines.

\section{Conclusions}

(1) About the Problem of the Relation between the Mathematical Model and the Material Behavior. Under identical loading, when the structure material is undergoing fatigue damage, the differences between the mathematical models to describe the material behavior are due to the degree of damage undergone at varied stages that makes the stiffness of the material change, which find that expressions in the curves $c b a B A_{1} A_{2}$ in evolutive process are turned to take place at the points $b, B$, and $A_{1}$. The slopes of the curves at each stage also are brought to change. The exponents in the equation also became from the $m_{1}=$ $-1 / b_{1}$ at crack forming stage to the $m_{2}=-1 / b_{2}$ at crack growth stage. The driving forces became from the $H_{1}\left(H_{1}^{\prime}\right)$ to the $K_{2}\left(K_{2}^{\prime}\right)$. The compositive material constants became from the $A_{1}$ to the $A_{2}$.

(2) About the Problem of Driving Force. It well known that the driving force of long crack growth in macro fracture mechanics is the stress intensity factor $K_{\mathrm{I}}$ but the driving force of microdamage at crack forming stage is defined by the author as the damage stress intensity factor $H_{1}^{\prime}$, and the driving force in microfracture mechanics is defined as the stress intensity factor $H_{1}$ of short-crack growth.

(3) About Problem of Dimensional Units. The stress intensity factor $H_{1}$ and the damage stress intensity factor $H_{1}^{\prime}$ of short crack at crack forming stage are all to describe the stress strain about the crack tip of micro-crack, the unit of the $H_{1}$ is $\mathrm{MPa} \cdot \sqrt[m_{1}]{m}$, and the unit of the $H_{1}^{\prime}$ is the MPa $\sqrt[m_{1}]{D_{1}}$. Both the units are different, but the unit of the damage stress intensity factor $H_{1}^{\prime}$ is the same as the unit of the stress, and the $H_{1}$ and the $H_{1}^{\prime}$ are all essentially the stress intensity factor and a relation of equivalents. And the stress intensity factor $K_{2}$ and the damage stress intensity factor $K_{2}^{\prime}$ of long crack at crack growth stage are all to describe the stress strain about the crack tip of long crack, the unit of the $K_{2}$ is $\mathrm{MPa} \cdot \sqrt{m}$, and the unit of $K_{2}^{\prime}$ is the MPa $\cdot \sqrt{D_{2}}$. Both the units are also different, but the unit of the damage stress intensity factor $K_{2}^{\prime}$ is also the same as the unit of the stress, and the $K_{2}$ and the $K_{2}^{\prime}$ are all essentially the stress intensity factor and a relation between equivalents. In addition, both values and dimensional units between the stress intensity factor of short crack and the stress intensity factor of long crack are also different under the condition of same crack size.

\section{Nomenclature}

(1) $D=$ damage variable in the whole process, $D_{\mu}, D_{1}=$ microdamage variable equivalent to micro-crack $a_{\mu}$ or short crack $a_{1}$ at the crack forming stage (first stage), and $D_{2}=$ damage variable at the crack growth stage (the second stage).

(2) $a_{\mu}, a_{1}=$ micro-, short-crack size at the crack forming stage (variable of the first stage), $a_{2}=$ macro-, longcrack size at the crack growth stage (variable of the second stage), $a_{10}=$ initial size of micro-crack forming (ordaining value), crack size $a_{\mathrm{th}}=$ corresponding to the threshold level $\Delta K_{\mathrm{th}}$, original size $a_{20}=a_{\mathrm{mac}}$ of macro-crack forming stage (ordaining value), and $a_{2 c}=$ critical size of long crack.

(3) $\Delta \sigma=$ nominal stress range, $\Delta \sigma_{0}=$ remote stress range, $\Delta \sigma / 2=$ stress amplitude, $\Delta \varepsilon_{p}=$ strain range, $\Delta \varepsilon_{p} / 2=$ strain amplitude, and $\sigma_{m}=$ mean stress.

(4) $\Delta G$ or $\Delta G^{\prime}=$ micro-crack stress intensity factor range or microdamage stress intensity factor range corresponding to microcrack size $a_{\mu}$ or microdamage $D_{\mu}$ under ultra-high cycle fatigue, $H_{1}=$ stress intensity factor of short crack, $H_{\text {mac }}=$ critical stress intensity factor of short crack, $H_{1}^{\prime}=$ damage stress intensity factor of short crack and $\Delta H_{1}^{\prime}$ or $\Delta H_{1}$ or $\Delta H_{1} / 2=$ stress intensity factor range or stress intensity factor amplitude relative to short-crack $a_{1} ; \Delta H_{1}^{\prime} / 2=$ damage stress intensity factor range or damage stress intensity factor amplitude relative to damage variable $D_{1}$.

$\Delta I$ or $\Delta I / 2=$ damage strain factor range or damage strain factor amplitude relative to short crack $a_{1}$.

(5) $a_{1}^{\prime}=$ fatigue strength exponent under ultra-high cycle fatigue, $b_{1}^{\prime}=$ fatigue strength exponent under high cycle fatigue, $c_{1}^{\prime}=$ fatigue ductility exponent under low cycle fatigue, $n_{1}=$ fatigue strength exponent in micro-crack growth rate equation under ultra-high cycle fatigue, $n_{1}=-1 / a_{1}^{\prime} ; m_{1}=$ fatigue strength exponent in short-crack growth rate equation under high-cycle fatigue, $m_{1}=-1 / b_{1}^{\prime}, m_{1}^{\prime}=$ fatigue ductility exponent in short-crack growth rate equation under low cycle fatigue, $m_{1}^{\prime}=-1 / c_{1}^{\prime}, b_{2}^{\prime}=$ fatigue strength exponent of the macro-crack growth stage under 
high-cycle fatigue, $c_{2}^{\prime}=$ the fatigue ductility exponent at the macro-crack growth stage under low-cycle fatigue, $m_{2}=$ the fatigue strength exponent in crack growth rate equation under high-cycle fatigue, $m_{2}=$ $-1 / b_{2}^{\prime}, m_{2}^{\prime}=$ the fatigue ductility exponent in crack growth rate equation under low-cycle fatigue, $m_{2}^{\prime}=$ $-1 / c_{2}^{\prime}$.

(6) $d D / d N=$ damage evolutive rate, $d D_{1} / d N_{1}=$ damage evolutive rate at the crack forming stage, $d D_{2} / d N_{2}$ $=$ damage evolutive rate at the macro-crack growth stage, $d a / d N=$ crack growth rate, $d a_{1} / d N_{1}=$ short crack growth rate at the crack forming stage, and $d a_{2} / d N_{2}=$ its rate at the macro-crack growth stage.

(7) $N_{\mathrm{oi}}=$ life of correspondance to medial damage variable $D_{\mathrm{oi}}$ or short-crack medial size $a_{\mathrm{oi}}$ at the first stage, and $N_{\mathrm{oj}}=$ life of correspondance to medial damage variable $D_{\mathrm{oj}}$ or long-crack medial size $a_{\mathrm{oj}}$ at the second stage.

(8) $K_{2}=K_{\mathrm{I}}=$ stress intensity factor of long crack, $K_{2}^{\prime}=$ damage stress intensity factor of long crack, $J$-integral of long crack; and crack tip opening displacement of long crack, $K_{m}=$ mean stress intensity factor, $\Delta K / 2$ $=$ stress intensity factor amplitude of correspondance to macro-crack $a_{2}, \Delta J / 2=J$-integral amplitude corresponding to macro-crack $a_{2}, \Delta \delta_{t} / 2=$ crack tip opening displacement amplitude corresponding to macro-crack $a_{2}$.

(9) $K_{1 c}=$ critical stress intensity factor corresponding to macro-crack critical $a_{2 c}, K_{\text {eff }}=$ effective stress intensity factor to be applicable in Paris's equation, $J_{c}=$ critical $J$-integral value corresponding to macrocrack critical $a_{2 c}$, and $\delta_{c}=$ critical crack tip opening displacement corresponding to macro-crack critical $a_{2 c}$.

\section{Acknowledgment}

The Authors thank sincerey the Zhejiang Province Natural Science fund Committee that gave support and provided subsidization of the research funds.

\section{References}

[1] Y. Yu and X. Liu, "Studies and applications of three kinds of calculation methods by describing damage evolving behaviors for elastic-plastic materials," Chinese Journal of Aeronautics, vol. 19, no. 1, pp. 52-58, 2005.

[2] Y. Yu, X. Jiang, J. chen, and Z. Wu, "The fatigue damage calculated with method of the multiplication $\Delta \varepsilon_{e} \Delta \varepsilon_{p}$," in Proceedings of the 8th International Fatigue Congress (Fatigue '02), vol. 5, pp. 2815-2822, Stockholm, Sweden, 2002.

[3] Y. Yu, "Fatigue damage calculated by the ratio-method to materials and its machine part," Chinese Journal of Aeronautics, vol. 16, no. 3, pp. 157-161, 2003.

[4] Y. Yu, Z. Li, Z. Bi, Y. Ma, and F. Xu, "To accomplish integrity calculations of structures and materials with calculation program in whole evolving process on fatigue-damage-fracture," in Proceedings of the UK Forum for Engineering Structural
Integrity's Ninth International Conference on Engineering Structural Integrity Assessment, pp. 180-183, Engineering Structural Integrity: Research, Development and Application, Beijing, China, 2007.

[5] Y. G. Yu, W. G. Pan, and Z. H. Li, "Correlations among curves equations and material parameters in the whole process on fatigue-damage-fracture of components, fracture and strength of solids," Key Engineering Materials, vol. 145-149, part 2, pp. 661-667, 1997.

[6] Y. Yu, B. Bi, Y. Ma, and F. Xu, "Damage calculations in whole evolving process actualized for the materials behaviors of structure with cracks to use software technique," in Proceedings of the 12th International Conference on Fracture Proceeding, pp. 12-19, Ottawa, Canada, 2009, (CD, Author Index Y. Yangui).

[7] B. Z. Marklen and V. A. Shbeichova, "Analysis of initiation and growth fatigue crack for pearlitic steels," Strength Problem, no. 4, pp. 12-21, 1990.

[8] Y. Murakami, S. Harada, T. Endo, H. Tani-Ishi, and Y. Fukushima, "Correlations among growth law of small cracks low-cycle fatigue law and applicability of Miner's rule," Engineering Fracture Mechanics, vol. 18, no. 5, pp. 909-924, 1983.

[9] Y. Murakami, "Measurement of mode II threshold stress intensity factor range $\Delta K_{\text {IIth }}$ for various steels and the threshold condition of biaxal fatigue crack growth," in Proceedings of the 7th International Fatigue Congress (Fatigue '99), vol. 2-4, p. 882, Higher Education Press, Beijing, China, 1999.

[10] Y. Yu, X. Liu, C. H. Zhang, and Y. Tan, "Fatigue damage calculated by ratio-method metallic material with small crack under unsymmetric cyclic loading," Chinese Journal of Mechanical Engineering, vol. 19, no. 2, pp. 312-315, 2006.

[11] Y. Yu, "Fatigue damage of materials with small crack calculated by the ratio method under cycle loading," Advanced Materials Research, vol. 9, pp. 79-86, 2003.

[12] Y. Yu and F. Xu, "Studies and application of calculation methods on small crack growth behaviors for elastic-plastic materials," Chinese Journal of Mechanical Engineering, vol. 43, no. 12, pp. 240-245, 2007.

[13] Y. G. Yu and E. J. Zhao, "Calculations to damage evolving rate under symmetric cyclic loading," in Proceedings of the 7th International Fatigue Congress (Fatigue '99), p. 1137, Beijing, China, 1999.

[14] D. Broek, Elementary Engineering Fracture Mechanics, Martinus Nijhoff, 3rd edition, 1982.

[15] K. Hellan, Introduction to Fracture Mechanics, McGraw-Hill, New York, NY, USA, 1984.

[16] Y. Yu, "A calculating parameter by way of using the damage variable D2 on intensity and life at crack growth stage," Journal of Materials Engineering, pp. 264-267, 2003 (Chinese).

[17] Y. Yu, "The correlation among each parameter in some equation on crack growth stage," in Advances in Fracture Research, vol. 3, pp. 1395-2002, Pergamon, Sydney, Australia, 1997. 

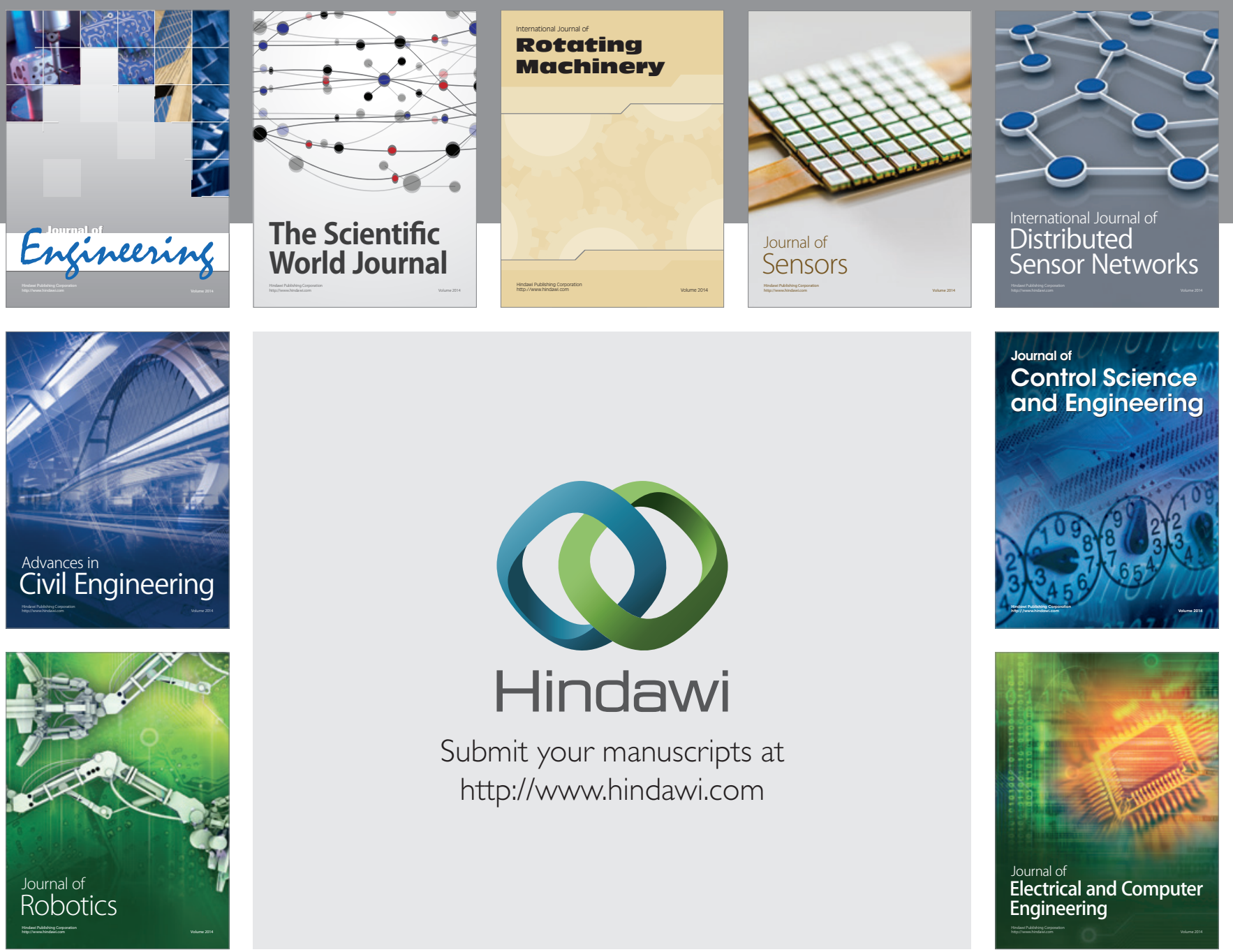

Submit your manuscripts at

http://www.hindawi.com
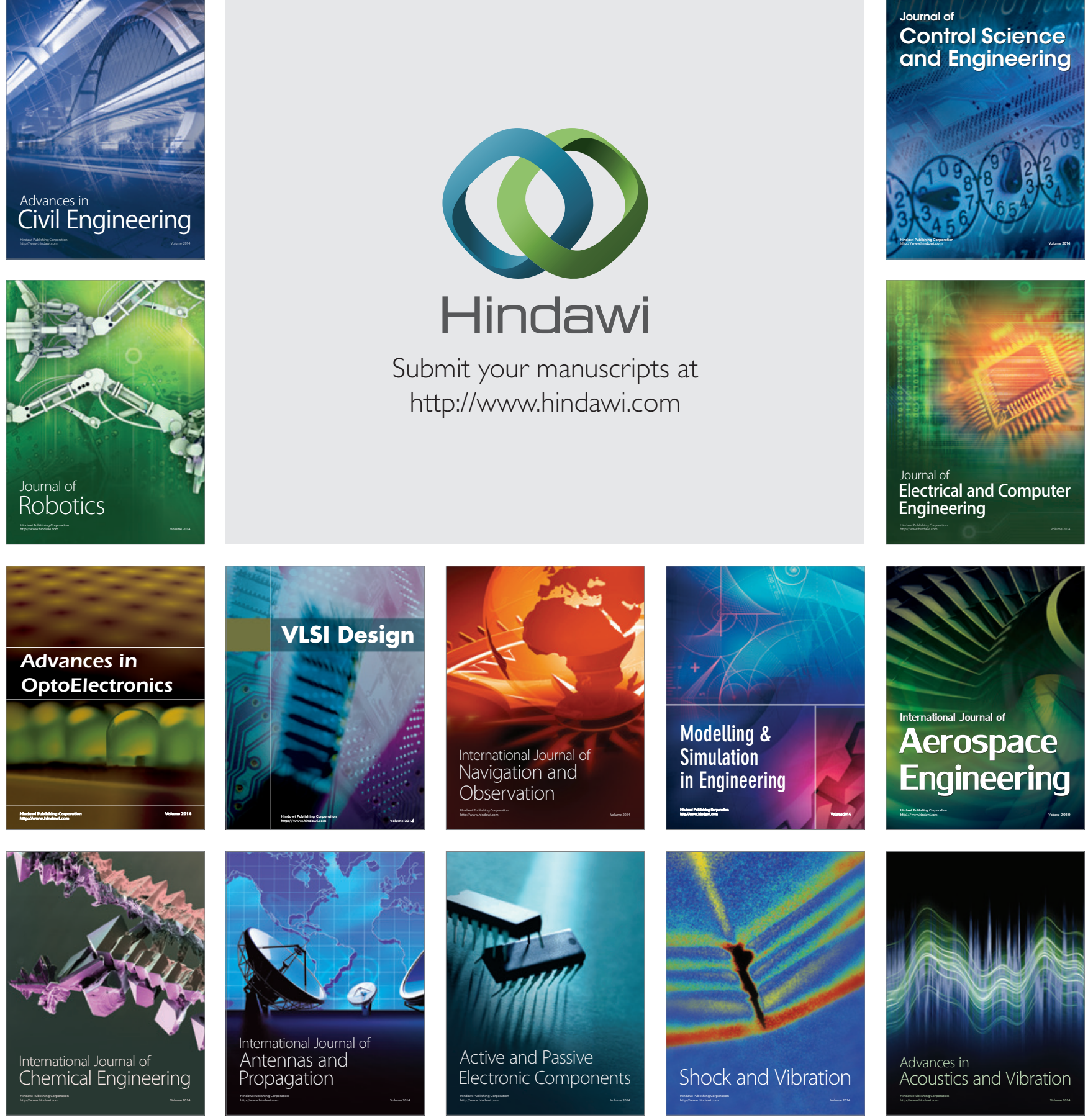